\section{Buried Bumper Syndrome: Endoscopic Management Using a Balloon Dilator}

A nursing-home resident with a percutaneous endoscopic gastrostomy (PEG) feeding tube (Freka CH 15; Fresenius, Bad Homburg, Germany) presented with resistance to flow of feed. Mobilization of the tube proved impossible. Endoscopy with the patient under intravenous sedation confirmed the buried bumper syndrome, with the internal bolster being completely buried. Only the lumen of the internal tube remained partially visible (Fig.1). Attempts at extraction using endoscopic snare or forceps proved unsuccessful.

We cut the external end of the tube at $3 \mathrm{~cm}$ from the abdominal wall and inserted a guide wire through the tubular lumen into the stomach. An esophageal balloon dilator was advanced through the endoscope into the stomach and pushed over the guide wire into the tubular lumen. The balloon was inflated to the maximum pressure recommended by the manufacturer until it remained solidly impacted in the PEG tube (Fig. 2). Traction of the endoscope and balloon catheter permitted extraction of the bumper through the stomach. Control endoscopy immediately thereafter showed no visible complication, and a new PEG tube was inserted during the same procedure. The patient's further course was uneventful.

The buried bumper is a complication of PEG that occurs in $2 \%$ to $6.1 \%$ of patients $[1,2]$ because excessive external traction leads to erosion of the internal bumper into the gastric wall.

Various internal and external techniques have been described for the removal of buried bumpers:

- grasping with a snare or forceps;

- needle-knife incision of the gastric wall [1];

- dilation of the opening using an externally placed balloon catheter [2];

- push-and-pull "T" technique with a tube fragment grasped in a snare [3];

- extraction using the tapered tip of a new PEG tube [4]; and

- external incision [5].

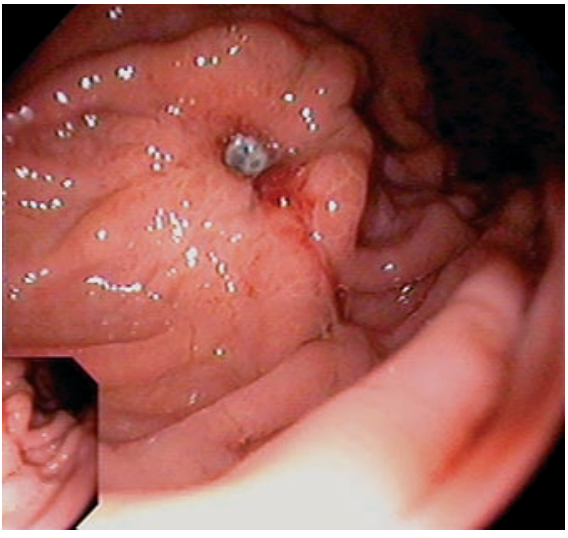

Figure 1 Endoscopic view of buried bumper in the gastric wall: only the lumen of the internal tube remains partially visible.

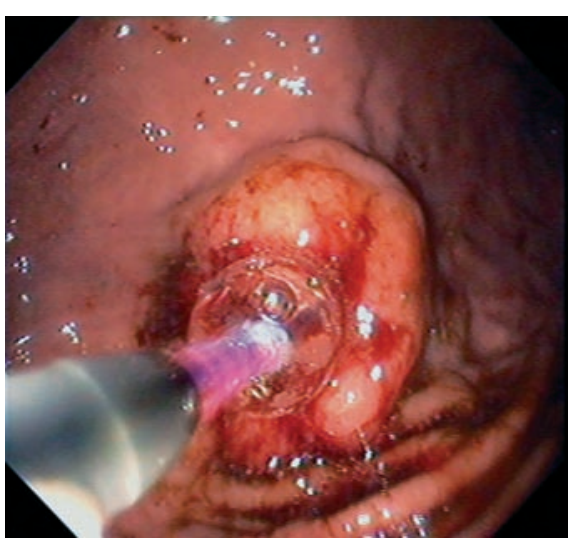

Figure 2 Intragastric view: traction on the buried bumper using a balloon dilator impacted in the percutaneous endoscopic gastrostomy (PEG) tube.

In some cases, surgical removal has been necessary [1].

Our technique may be added to the arsenal of simple methods for the extraction of a buried bumper before the more risk-prone incision techniques, or even surgery, are employed.

\section{P. Strock, J. Weber}

Service d'HépatoGastroEntérologie, Centre Hospitalier, Luxembourg.

\section{References}

${ }^{1}$ Braden B, Brandstaetter M, Caspary WFet al. Buried bumper syndrome: treatment guided by catheter probe US. Gastrointest Endosc 2003; 57: 747 -750

2 Ma MM, Semlacher EA, Fedorak RNet al. The buried gastrostomy bumper syndrome: prevention and endoscopic approaches to removal. Gastrointest Endosc 1995; 41: $505-508$

${ }^{3}$ Boyd JW, DeLegge MH, Shamburek RDet al. The buried bumper syndrome: a new technique for safe, endoscopic PEG removal. Gastrointest Endosc 1995; 41: 508- 511

${ }^{4}$ Venu RP, Brown RD, Pastika BJet al. The buried bumper syndrome: a simple management approach in two patients. Gastrointest Endosc 2002; 56: $582-$ 584

${ }^{5}$ Frascio F, Giacosa A, Piero Pet al. Another approach to the buried bumper syndrome. Gastrointest Endosc 1996; 43: 263

\section{Corresponding Author}

\section{P. Strock, M.D.}

Service d'HépatoGastroEntérologie, Centre Hospitalier

4 , rue Barblé

1210 Luxembourg

Fax: +352-44-116902

E-mail: strock.paul@chl.lu 